\title{
Forecasting volatility of wind power production
}

Zhiwei Shen*

Matthias Ritter*

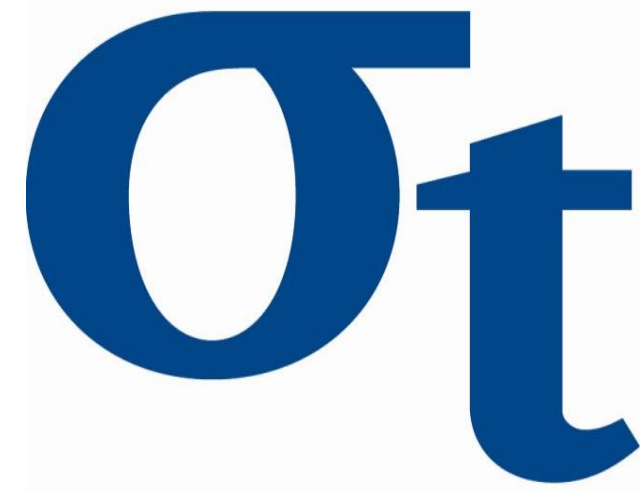

9

寸

6

* Humboldt-Universität zu Berlin, Germany

This research was supported by the Deutsche Forschungsgemeinschaft through the SFB 649 "Economic Risk".

http://sfb649.wiwi.hu-berlin.de ISSN 1860-5664 


\title{
Forecasting volatility of wind power production*
}

\author{
Zhiwei Shen $^{\mathrm{a} * *}$ and Matthias Ritter ${ }^{\mathrm{a}}$
}

\begin{abstract}
The increasing share of wind energy in the portfolio of energy sources highlights its uncertainties due to changing weather conditions. To account for the uncertainty in predicting wind power production, this article examines the volatility forecasting abilities of different GARCH-type models for wind power production. Moreover, due to characteristic features of the wind power process, such as heteroscedasticity and nonlinearity, we also investigate the use of a Markov regime-switching GARCH (MRS-GARCH) model on forecasting volatility of wind power. The realized volatility, which is derived from lower-scale data, serves as a benchmark for the latent volatility. We find that the MRS-GARCH model significantly outperforms traditional GARCH models in predicting the volatility of wind power, while the exponential GARCH model is superior among traditional GARCH models.
\end{abstract}

Keywords: Wind energy, volatility forecasting, GARCH models, Markov regime-switching, realized volatility

JEL code: C22, Q42, Q47

\section{Introduction}

Increasing energy demand and the negative impact of fossil energy consumption on climate change impacts have led to a worldwide boom of renewable energies such as wind energy. The global cumulative installed wind energy capacity increased from $24 \mathrm{GW}$ in 2001 to $370 \mathrm{GW}$ in 2014 and is expected to reach 596 GW until 2018 (GWEC, 2014; 2015). However, relying on renewable energy to meet increasing energy demand is still problematic. One of the main concerns of renewable energy production is its riskiness due to changing weather conditions. This is particularly true for wind energy production, which is the most rapidly expanding energy source. Volume risk is an important economic issue since energy is a non-storable commodity. In view of the increasing share of risky renewable energies in the portfolio of

\footnotetext{
* The authors would like to thank Martin Odening and Brenda López Cabrera for their helpful comments. The financial support from the German Research Foundation via the CRC 649 "Economic Risk", HumboldtUniversität zu Berlin, is gratefully acknowledged.

${ }^{a}$ Humboldt-Universität zu Berlin, Department of Agricultural Economics, Philippstr. 13, 10115 Berlin, Germany.

** Corresponding author: zhiwei.shen@agrar.hu-berlin.de, Tel.: +49 (0) 30209346834, Fax: +49 (0) 30209346841.
} 
energy sources a quantification of the production risk has gained considerable attention. ${ }^{1}$ Interest in prediction of wind energy production is manifold: In the long run (several years), investors want to predict their returns on investments in wind energy production. In the short run (several hours to days), grid operators have to make decisions about energy scheduling in order to balance supply and demand on a regional or national grid. Moreover, energy traders want to make informed decisions on how much they can offer or bid in the next trading cycle. This requires reliable forecasts of the output of wind energy farms.

Two main streams of approaches and models have been proposed to generate wind power forecasts. The first type are physical or meteorological models. They rely on Numerical Weather Prediction models to determine meteorological forecasts, which are then transformed into wind power forecast via a power curve (Monterio et al., 2009). The second type are mathematical or statistical approaches. They use the statistical models (e.g., time series models, data mining models such as neural networks or support vector machines) to identify the spatialtemporal relationship between the wind power production and explanatory variables (e.g., historical wind power data). Based on this relationship the wind power forecasts are estimated from the observed explanatory variables (Brown et al., 1984; Bilgili et al., 2007). The strengths of different models rest on the different forecast horizons. An overview about the various modelling approaches can be found in Giebel et al. (2011) and Kusiak et al. (2013).

Regardless of these approaches and models, two kinds of forecasts can be considered. Early research focused on point forecasts of wind energy production, i.e., a single value of conditional expectation of wind power production is predicted. To make optimal decisions for energy participants, however, it is not sufficient to know only the expected wind power production. The actual production most likely deviates from the forecast and their difference causes imbalance costs for market participants. Therefore, participants in the energy market need an assessment of the uncertainty involved in the prediction. To account for the uncertainty of wind power production, probabilistic forecasts of wind energy production have been proposed (Bremnes, 2004; Pinson et al., 2007; Trombe et al., 2012). Probabilistic forecasts are more flexible than point forecasts and can be quantile or interval forecasts (Bremnes, 2004; Anastasiades and McSharry, 2013) or full predictive density forecasts (Lau and McSharry, 2010).

\footnotetext{
${ }^{1}$ Actually, the Economist Intelligence Unit (2011) reports from a survey among 280 executives and investors in the renewable energy industry that $66 \%$ percent of the respondents were concerned about volumetric risk in wind energy production.
} 
One crucial parameter that captures the uncertainty of wind power production in probabilistic forecasting is volatility. It is also a determinant of financial risk management instruments such as insurance or wind derivatives. To measure the volatility of wind power production, characteristic features of wind data have to be taken into account. First of all, it has to be recognized that not only wind speed but also its volatility is usually time-varying. In a medium term perspective, seasonal effects of wind activity have to be considered (Šaltytė-Benth and Benth, 2010). In addition, one can observe stochastically time-varying heteroscedasticity similar to financial markets (Lau and McSharry, 2010). Moreover, wind power production can be affected by ramp events when energy output changes by a substantial fraction of the capacity within short time. Ramp events can be caused by a passage of large scale weather systems or by thunderstorms. As a result, high wind speed shutdowns may occur, causing a rapid decrease in wind power production.

So far, a variety of volatility models have been applied either to wind speed data or to wind power data to capture time-varying heteroscedasticity. Alexandridis and Zapranis (2013) estimate an ARIMA model for daily average wind speed data and model seasonal variation of the volatility with a truncated Fourier series. The prevalent models, however, are autoregressive conditional heteroscedasticity (ARCH) and generalized autoregressive conditional heteroscedasticity (GARCH). Tastu et al. (2014) use an ARCH model to generate the variances in the probabilistic forecasts of wind power production for an offshore wind farm in Denmark. Liu et al. (2011) evaluate the effectiveness of ARMA-GARCH approaches for modeling the mean and volatility of wind speed, including different GARCH models such as EGARCH and TGARCH. Lau and McSharry (2010) identify an ARIMA-EGARCH model for aggregated wind power data in Ireland and produce forecasts of the wind power density up to 24 hours ahead. However, wind speed or wind power data exhibit random breaks and nonlinear behaviors. The classic ARMA and ARMA-GARCH models may be too restrictive to capture such nonlinear dynamic process. Recently, a Markov regime switching model has been proposed and found suitable to model the dynamic behavior of wind power (Pinson et al., 2008) and wind speed (Song et al., 2014). A nice feature of this model is that it allows for reflecting the impact of random external factors since the regime switching process is driven by a Markov chain. To account for the nonlinearity and heteroscedasticity of volatility, we propose the use of Markov regime switching GARCH (MRS-GARCH) model as an alternative for modeling the volatility of wind power production in this article. 
In contrast to previous studies aiming at forecasting wind power production, this paper focuses on volatility forecasts and explores the performance of volatility forecasting within the class of GARCH models including Markov regime switching GARCH. A volatility forecast comparison can be difficult since the true, latent volatility is unobservable. As a result, the predicted value must be compared with an ex post proxy of volatility, e.g., realized volatility. The concept of realized volatility was initially introduced in financial market due to the availability of high frequency financial data (Andersen et al., 2003). The daily volatility of stock price is calculated by summing squared intraday returns. As a model-free estimator, realized volatility has often been used as an ex post proxy to evaluate the volatility forecast models in financial and energy markets (Marcucci, 2005; Brownlees et al., 2011; Byun and Cho, 2013). To our knowledge, realized volatility has not been exploited in the wind power production analysis so far.

In this article we use wind power production from a wind farm in Germany. Since the interest of energy market participants traditionally lie on the hourly forecast as required by the market structure (Trombe and Pinson, 2012), the hourly resolution of wind power production is chosen to generate the hourly volatility forecast through the considered models. To evaluate the forecasted volatility, we are able to access to higher frequency data of wind power production reported for an interval of 10 minutes and then derive the realized volatility as the ex post proxy of hourly volatility.

The contribution of this article to the existing literature is threefold. First, we develop a Markov regime switching GARCH model to describe the time-varying volatility of wind power production. This model could allow us to capture the nonlinearity of wind power production due to changing weather conditions or ramp events. Second, an assessment of the performances of the class of GARCH volatility forecasting models is provided. The results show that Markov regime switching GARCH seems to outperform other GARCH models and EGARCH perform second best. Third, this is the first time to explore the use of realized volatility for wind power production. We find that an instant ramp event within an hour causes a bias in realized volatility estimator for hourly spot volatility.

The rest of the paper is structured as follows. The next section describes the volatility forecasting methodology: we briefly give an overview of the traditional GARCH models, and then describe the Markov regime switching GARCH model in detail as well as forecast evaluation criteria. In the subsequent section, these models are applied to wind power data from 
a wind farm in Germany. We present the comparison of those volatility forecasting models, insample and out-of-sample respectively. The last section provides conclusion and discussion on the benefit of Markov regime switching GARCH model and offers suggestions for further research.

\section{Volatility Forecasting Methodology}

\subsection{Traditional GARCH Models}

Prior to modelling the volatility of wind power production, an appropriate Autoregressive (AR) model that captures the time-varying means of wind power data is often used (Trombe et al., 2012). Considering a time series of wind power $\left\{y_{t}\right\}$, we use the $\operatorname{AR}(k)$ model given by:

$$
y_{t}=c+\sum_{i=1}^{k} \phi_{i} y_{t-i}+\varepsilon_{t}
$$

where $c$ is a constant, $k$ the order of autoregressive terms, $\phi_{i}$ the $i$ th autoregressive coefficient and $\varepsilon_{t}$ the error term. Suppose that the error term $\varepsilon_{t}$ has a time-varying variance and it can be represented as:

$$
\varepsilon_{t}=\eta_{t} h_{t}
$$

where $\eta_{t}$ is an iid random variable with mean 0 and variance $1 ; h_{t}$ is the conditional standard deviation at $t$ given the information set $\Omega_{t-1}=\left\{y_{t-1}, \ldots, y_{1}\right\}$ at $t-1$, i.e., $h_{t}^{2}=V\left[\varepsilon_{t} \mid \Omega_{t-1}\right]$. The specification of $h_{t}^{2}$ determines the conditional variance evolution and the forecast of volatility at the next periods. To determine the specification of the conditional variance, a variety of $\operatorname{GARCH}$ models have been developed. The traditional $\operatorname{GARCH}(p, q)$ model was proposed by Bollerslev (1986) consisting of the order $k$ of the moving average ARCH term and the order $m$ of the autoregressive GARCH term. It can be written as:

$$
h_{t}^{2}=\omega+\sum_{i=1}^{k} \alpha_{i} \varepsilon_{t-i}^{2}+\sum_{j=1}^{m} \beta_{j} h_{t-j}^{2},
$$

where $\omega$ is the constant term, $\varepsilon_{t-i}^{2}$ the ARCH term, $h_{t-j}$ the GARCH term, and $\left(\alpha_{1}, \ldots, \alpha_{p}, \beta_{1}, \ldots, \beta_{q}\right)$ are the coefficient parameters to be estimated. It indicates that the variance depends on previous errors and also previous conditional variances. To ensure a stationary and positive conditional variance, the parameters are confined to satisfy $\omega>0, \alpha_{i} \geq$ $0, \beta_{i} \geq 0$ and $\sum_{i=1}^{k} \alpha_{i}+\sum_{j=1}^{m} \beta_{j}<1$ (Tsay, 2010). Although any order of GARCH model is possible, in general a $\operatorname{GARCH}(1,1)$ is sufficient to capture the volatility clustering in the data. 
It is called the standard GARCH model, denoted as SGARCH in this paper. Then, Equation (3) reduces to:

$$
h_{t}^{2}=\omega+\alpha_{1} \varepsilon_{t-1}^{2}+\beta_{1} h_{t-1}^{2},
$$

The important features of this GARCH model are its mean reversion due to the stationary condition $\left(\alpha_{1}+\beta_{1}<1\right)$ and its symmetry (i.e., the sign of the error term has no influence on the future volatility).

\section{Variants of GARCH models}

To account for asymmetric effects in volatility forecasting, several GARCH models have been developed. In this paper, we consider four models from the vast literature, namely exponential GARCH (EGARCH), threshold GARCH (TGARCH), Glosten-Jagannathan-Runkle GARCH (GJR GARCH) and nonlinear GARCH (NGARCH). We chose these four model for the following reasons: first, these GARCH models have been widely recommended due to their simplicities and demonstrated abilities to forecast volatility (Brownlees et al., 2011); second, Liu et al. (2011) applied the above-mentioned GARCH models for wind speed volatility and found that the volatility of wind speed has the nonlinear and asymmetric time-varying properties. Since wind speed is the main driving factor of wind power production, it is reasonable to refer to wind speed modelling. A brief overview of these GARCH models and how they deal with the asymmetry is provided below ${ }^{2}$.

The EGARCH model was proposed by Nelson (1991) in the form of the log of variance as

$$
\begin{aligned}
\log \left(h_{t}^{2}\right)=\omega & +\sum_{i=1}^{k} \alpha_{i}\left[\left|\eta_{t-i}\right|-\mathrm{E}\left(\left|\eta_{t-i}\right|\right)\right]+\sum_{j=1}^{m} \beta_{j} \log \left(h_{t-j}^{2}\right) \\
& +\sum_{i=1}^{p} \gamma_{i}\left(\eta_{t-i}\right),
\end{aligned}
$$

where $\eta_{t-i}=\varepsilon_{t-i} / h_{t-i}, \alpha_{i}$ and $\gamma_{i}$ capture the asymmetric effect of the sign and the magnitude of $\eta_{t}$ on the volatility. For example, when $\gamma_{i}<0$, the negative value of $\varepsilon_{t-i}$ results in higher volatility than the positive value in EGARCH. Unlike the GARCH model in Equation (3), there is no restriction on the parameters in $\mathrm{EGARCH}$.

The TGARCH developed by Zakoian (1994) models the conditional standard deviation as:

\footnotetext{
${ }^{2}$ A more detailed analysis of these asymmetric models can be found in Hentschel (1995).
} 


$$
h_{t}=\omega+\sum_{i=1}^{k} \alpha_{i}\left(\left|\varepsilon_{t-i}\right|-\gamma_{i} \varepsilon_{t-i}\right)+\sum_{j=1}^{m} \beta_{j} h_{t-j}
$$

where $\omega>0, \alpha_{i} \geq 0, \beta_{i} \geq 0$ and $\left|\gamma_{i}\right| \leq 1$. Similar to TGARCH, Glosten et al. (1993) introduced the GJR GARCH with the focus on the variance instead of the standard deviation. Formally stated:

$$
h_{t}^{2}=\omega+\sum_{i=1}^{k} \alpha_{i}\left(\left|\varepsilon_{t-i}\right|-\gamma_{i} \varepsilon_{t-i}\right)^{2}+\sum_{j=1}^{m} \beta_{j} h_{t-j}^{2},
$$

Finally, the NGARCH, also known as nonlinear asymmetric GARCH, was developed by Engle and $\mathrm{Ng}(1993)$ in the following specification:

$$
h_{t}^{2}=\omega+\sum_{i=1}^{k} \alpha_{i}\left(\varepsilon_{t-i}-\gamma_{i} h_{t-i}\right)^{2}+\sum_{j=1}^{m} \beta_{j} h_{t-j}^{2},
$$

where $\omega>0, \alpha_{i} \geq 0, \beta_{i} \geq 0$. In the TGARCH, GJR GARCH and NGARCH, $\gamma_{i}$ reflects the asymmetric effect. When $\gamma_{i}>0$, the models indicate that negative error terms increase future volatility by a larger amount than positive ones of the same magnitude. In the application, we only use these GARCH models with the order $(1,1)$.

\subsection{Markov Regime Switching GARCH Model}

When inspecting time series of wind power production, continuous periods with fluctuations of lower and higher magnitudes are often easily noticed and call for the use of regime-switching model. The use of Markov regime switching model proposed by Hamilton (1989) has received a growing interest in the wind power community due to its superior ability to account for structure breaks and random changes in the dynamic process (Pinson et al., 2008; Trombe et al., 2012). The basic idea of this model is allowing the parameters of the model to switch across different regimes (states or phases) according to a Markov process, which is governed by a state variable $s_{t}$. In other words, it implies a mixture of processes with different characteristics according to the probability of being in each state. Early studies have mainly applied Markov regime switching models to forecast average wind power production, and the application to volatility forecasting is still rare. In this paper, we allow the regime-switching in both, average wind power production and its volatility, resulting in an extension of the Markov regimeswitching model with different GARCH specifications in each regime. A difficulty of the regime switching model is the determination of the number of states since the underlying regimes themselves are unobserved and econometric tests for choosing the optimal number of regimes are still under development. As a result, almost all applications of Markov regime 
switching models assume two or three different regimes (Balcilar et al., 2015; Lammerding et al., 2013; Marcucci, 2005). Similarly, we follow Trombe et al. (2012) and consider only two regimes in the Markov regime switching GARCH (MRS-GARCH) model for forecasting volatility of wind power production, i.e., $s_{t} \in\{1,2\}$.

\section{Description of MRS-GARCH model}

The regime switching process follows a first order Markov chain with transition probability:

$$
\mathrm{P}\left(s_{t}=j \mid s_{t-1}=i\right)=p_{i j}
$$

that indicates the probability of the regime switching from state $i$ at time $t-1$ into state $j$ at time $t$. By definition, the probability of switching from state $i$ at $t-1$ into state $i$ at $t$ is: $p_{i i}=$ $1-p_{i j}$ when only two regimes are assumed. The transition matrix $\mathbf{P}$, which describes all the probabilities of regimes switching from one to the other, is given by:

$$
\mathbf{P}=\left[\begin{array}{ll}
p_{11} & p_{21} \\
p_{12} & P_{22}
\end{array}\right]=\left[\begin{array}{cc}
p & 1-q \\
1-p & q
\end{array}\right] .
$$

Under the framework of MRS-GARCH, we allow the regime-switching in both, the mean and the volatility of wind power production, and each regime is characterised by different parameter sets. Thus, Equation (1) for modelling conditional mean equation of wind power production changes to:

$$
y_{t}=c^{(i)}+\sum_{i=1}^{k} \phi_{i}^{(i)} y_{t-i}+\varepsilon_{t},
$$

where $i=1,2$ and $\varepsilon_{t}=\eta_{t} h_{t}$ as in Equation (2). However, the specification of a GARCH model for the conditional variance becomes problematic since the autoregressive structure of the conditional variance makes the specification path-dependent. The conditional variance of $\varepsilon_{t}$ being in state $(i)$ at time $t$, given the past unobservable regime path $\left(s_{t}, s_{t-1}, \ldots, s_{1}\right)$ and information set $\Omega_{t-1}$ at time $t-1$, is $h_{t}^{2 \mid(i)}=V\left[\varepsilon_{t} \mid\left(s_{t}, s_{t-1}, \ldots, s_{1}\right), \Omega_{t-1}\right]$. In the regime switching context, a GARCH model with path dependency would be computationally intractable and infeasible because the number of regime paths grows exponentially with the number of observations. To avoid this problem of path dependence, Klaassen (2002) proposed simplifications to the GARCH model, which integrates out the past regimes to get the conditional expectation of the past conditional variance by also taking into account the current regime. As a result, the expression of $\operatorname{GARCH}(1,1)$ for the conditional variance can be written as: 


$$
h_{t}^{2 \mid(i)}=\omega^{(i)}+\alpha_{1}^{(i)} \varepsilon_{t-1}^{2}+\beta_{1}^{(i)} \mathrm{E}_{t-1}\left\{h_{t-1}^{2 \mid(i)} \mid s_{t}\right\} .
$$

More details can be found in Klaassen (2002). The advantage of this approach is that it allows to calculate the log likelihood function and multi-step ahead volatility forecasts recursively as in standard GARCH models. The multi-step volatility forecasts can be computed as the weighted average of multi-step volatility forecasts in each regime, where the weights are the predicted probability of being in each regime.

\section{Estimation}

The specification of a Markov regime switching model requires the estimation of the unobservable regime sequence $\left\{s_{t}\right\}$ and the parameter set in each regime. Since the state variable $s_{t}$ is unobservable, the inference of state variable can only be determined based on the data. The conditional probability of $s_{t}$ being in regime $j$, given the information set $\Omega_{t}$ at time $t$ and parameters $\Theta$ is:

$$
\xi_{s_{t} \mid \Omega_{t}}^{j}=\mathrm{P}\left(s_{t}=j \mid \Omega_{t}, \Theta\right)
$$

where $\Theta$ refers to all the parameters that specify the stochastic process. An important step that allows for iteratively calculating $\xi_{t}^{j}$ is to reformulate Equation (13) via the definition of conditional probability:

$$
\xi_{s_{t} \mid \Omega_{t}}^{j}=\mathrm{P}\left(s_{t}=j \mid \Omega_{t}, \Theta\right)=\frac{f\left(y_{t}, s_{t}=j \mid \Omega_{t-1}, \Theta\right)}{f\left(y_{t} \mid \Omega_{t-1}, \Theta\right)},
$$

where the numerator is the conditional joint density of $y_{t}$ and $s_{t}$ being in state $j$ given $\Omega_{t-1}, \Theta$, while the denominator is the conditional density of $y_{t}$ given $\Omega_{t-1}, \Theta$. The numerator can be determined by:

$$
f\left(y_{t}, s_{t}=j \mid \Omega_{t-1}, \Theta\right)=\xi_{s_{t} \mid \Omega_{t-1}}^{j} f\left(y_{t} \mid s_{t}=j, \Omega_{t-1}, \Theta\right),
$$

where $\xi_{s_{t} \mid \Omega_{t-1}}^{j}=\mathrm{P}\left(s_{t}=j \mid \Omega_{t-1}, \Theta\right)$ is the forecast of the probability of $s_{t}$ being in state $j$ given $\Omega_{t-1}$ at $t-1$ and $\Theta$. The forecast of the probability matrix can be obtained via the transition matrix $\mathbf{P}$ as:

$$
\xi_{s_{t} \mid \Omega_{t-1}}=\mathbf{P} \xi_{s_{t-1} \mid \Omega_{t-1}}
$$

The conditional density $f\left(y_{t} \mid s_{t}=j, \Omega_{t-1}, \Theta\right)$ depends on the specification of the model and the distribution of error distribution in each regime.

The denominator in Equation (14) can be calculated as the sum of conditional joint densities for all regimes (in our case the number of regimes is 2): 


$$
f\left(y_{t} \mid \Omega_{t-1}, \Theta\right)=\sum_{j=1}^{2} f\left(y_{t}, s_{t}=j \mid \Omega_{t-1}, \Theta\right) .
$$

Finally, inserting Equations (15), (16) and (17) into Equation (14) yields:

$$
\begin{aligned}
\xi_{s_{t} \mid \Omega_{t}}^{j} & =\mathrm{P}\left(s_{t}=j \mid \Omega_{t}, \Theta\right) \\
& =\frac{\sum_{i=1}^{2} p_{i j} \xi_{s_{t-1} \mid \Omega_{t-1}}^{i} f\left(y_{t} \mid s_{t}=j, \Omega_{t-1}, \Theta\right)}{\sum_{j=1}^{2} \sum_{i=1}^{2} p_{i j} \xi_{s_{t-1} \mid \Omega_{t-1}}^{i} f\left(y_{t} \mid s_{t}=j, \Omega_{t-1}, \Theta\right)} .
\end{aligned}
$$

The corresponding conditional log likelihood of the observations is given by:

$$
\ell\left(y_{1}, y_{2}, \ldots, y_{T} \mid \Theta\right)=\sum_{t=1}^{T} \log f\left(y_{t} \mid \Omega_{t-1}, \Theta\right) .
$$

The maximum likelihood estimators can be obtained by maximizing Equation (19).

\subsection{Forecast Evaluation}

To evaluate the predictive accuracy of different models, statistical loss functions are typically employed. A model that has a smaller average loss is considered to be more accurate. However, many researchers have highlighted that a few extreme observations may have an excessively large impact on the outcomes of forecast evaluation and comparison tests and have suggested to use loss functions that are less sensitive to large observations (Bollerslev and Ghysels, 1994; Andersen et al., 1999; Poon and Granger, 2003). Therefore, instead of using one particular statistical loss function, we here adopt different statistical loss functions, namely Root Mean Square Error (RMSE), RMSE-LOG, Mean Absolute Error (MAE), MAE-LOG and QLIKE (Patton, 2011; Byun and Cho, 2013). With the forecasted volatility and the actual volatility at hand, RMSE, RMSE-LOG, MAE, MAE-LOG and QLIKE are defined as:

$$
\begin{gathered}
R M S E=\sqrt{\frac{1}{N} \sum_{t=T+1}^{T+N}\left(\hat{\sigma}_{t}^{2}-\hat{h}_{t}^{2}\right)^{2}} \\
R M S E=\sqrt{\frac{1}{N} \sum_{t=T+1}^{T+N}\left(\log \left(\hat{\sigma}_{t}^{2}\right)-\log \left(\hat{h}_{t}^{2}\right)\right)^{2}} \\
M A E=\frac{1}{N} \sum_{t=T+1}^{T+N}\left|\hat{\sigma}_{t}^{2}-\hat{h}_{t}^{2}\right|
\end{gathered}
$$




$$
\begin{gathered}
M A E=\frac{1}{N} \sum_{t=T+1}^{T+N}\left|\log \left(\hat{\sigma}_{t}^{2}\right)-\log \left(\hat{h}_{t}^{2}\right)\right| \\
Q L I K E=\frac{1}{N} \sum_{t=T+1}^{T+N}\left(\log \left(\hat{h}_{t}^{2}\right)+\frac{\hat{\sigma}_{t}^{2}}{\hat{h}_{t}^{2}}\right),
\end{gathered}
$$

where $\hat{\sigma}_{t}^{2}$ is the ex post proxy of conditional variance representing the actual volatility at $t, t>$ $T$, and $\hat{h}_{t}^{2}$ is a volatility forecast at $t$ and $N$ is the testing horizon. In our paper, we use realized volatility as $\hat{\sigma}_{t}^{2}$ (see Section 3.1).

To determine if the predictive accuracies of the competing models are significantly different, we use the Diebold-Mariano (DM) test (Diebold and Mariano, 1995). Such a test is based on the loss function differential between model $a$ and model $b$, defined as $d_{t}=\left[g\left(e_{a, t}\right)-\right.$ $\left.g\left(e_{b, t}\right)\right]$ where $g(\cdot)$ means a loss function, $e_{\cdot, t}$ corresponding forecast errors from the competing models. In our paper we focus on two loss functions: square error loss function and absolute error loss function. The null hypothesis of DM test is no difference in the accuracy of the two competing forecasts, i.e., $\mathrm{E}\left(d_{t}\right)=0$. The DM test statistic takes the form of a t-statistic, i.e., $D M=\bar{d} / \sqrt{\widehat{V}(\bar{d})} \sim N(0,1)$, where $\bar{d}=\frac{1}{n} \sum_{t=1}^{n} d_{t}$, and $\hat{V}(\bar{d})$ is the asymptotic variance of $\bar{d}$. For more details, we refer to Diebold and Mariano (1995). The null hypothesis is rejected or accepted based on the DM test statistic and the critical value.

\section{Empirical Volatility Forecasting Results}

\subsection{Wind Power Data}

Volatility models have been applied to wind speed data as well as to wind power production data. Wind speed data at weather stations have the advantage of being easily accessible, and a transformation of wind speed data into energy production data is possible by means of rather simple power curves that take into account turbine types, turbine height and other technical specifications. This is found to be quite useful because mostly researchers do not have access to wind power data due to the commercial sensitivity. However, the distance between weather stations and wind turbines results in a bias on transformed production data. Alternatively, wind speed data from reanalysis data could reduce the bias, but empirical evidence showed that the $R^{2}$ of estimated power curves rarely exceeds 0.76 (Ritter et al, 2015) and thus actual production risk is underestimated. Moreover, the power curve may be different with the different time of 
year and different environmental conditions (Anastasiades and McSharry, 2013). To avoid this kind of basis risk, we prefer to work with observed instead of transformed production data.

Wind power production data are collected from a wind farm located in the middle of Germany (see Figure 1). The wind farm consists of six wind turbines with same maximum capacity, namely 2.3 MW. The wind power data used in the estimation and forecasting of all models are recorded every hour from 1 October 2012 to 7 January 2014 for a total of 10,945 observations. The reason to justify the choice of the hourly resolution is that energy market participants are traditionally interested at the hourly forecast as required by the market structure (Trombe and Pinson, 2012). Following Anastasiades and McSharry (2013) and Pinson (2012), time series data are normalized and expressed as a percentage of the wind farm capacity, which range in the interval $[0,1]$ (see Figure 2). Missing values due to technical disorder and long-time shutdown of the wind farm are neglected. For in-sample estimation, we use the data from 1 October 2012 to 31 December 2013, while the data from 1 January to 7 January 2014 are used for out-of-sample evaluation. Parameters for the considered models in the forecast are estimated on an increasing sample as new information arrives. For example, when estimating a GARCH model using data from from 1 October 2012, 0:00, to 31 December 2013, 24:00, we obtain a one-step-ahead (i.e., one-hour-ahead) forecast for 1:00 on 1 January 2014. By increasing the sample by one hour and re-estimating the model for the new sample until 1 January $2014,1: 00$, we obtain a forecast for 2:00 on 1 January 2014. This estimation is repeated until a forecast for 23:00 on 7 January 2014 is achieved. As a result, the estimation needs to be repeated 168 times. For multi-step-ahead forecast, the number of repetitions will reduce by the forecast horizon. We calculate the multi-step-ahead volatility forecast by summing up the hourly ahead volatility forecast over next periods since practitioners and risk managers might be more interested in the stability of the grid of wind power production over the next period than multi-step ahead one-hour volatility.

Since the true volatility is latent and unobservable, we use the realized volatility as the ex post proxy to compare with the forecast from the models. The realized volatility is based on the cumulative squared deviation over different time intervals. When we divide one hour into $m$ periods and denote $y_{t, i}(i=0, \ldots, m)$ as an observation for the $60 / m$-minute wind production at time $t$, the realized volatility within one hour can be calculated as:

$$
\hat{\sigma}_{R V, t}^{2}=\sum_{i=1}^{m}\left(y_{t, i}-y_{t, i-1}\right)^{2}
$$


In this paper, we use wind power data reported for an interval of 10 minutes from 1 January to 7 January 2014 to calculate the realized volatility for hourly wind production, i.e., $m=6$. To calculate the realized volatility at $h$ step ahead, we sum the hourly realized volatility over the $h$ steps.

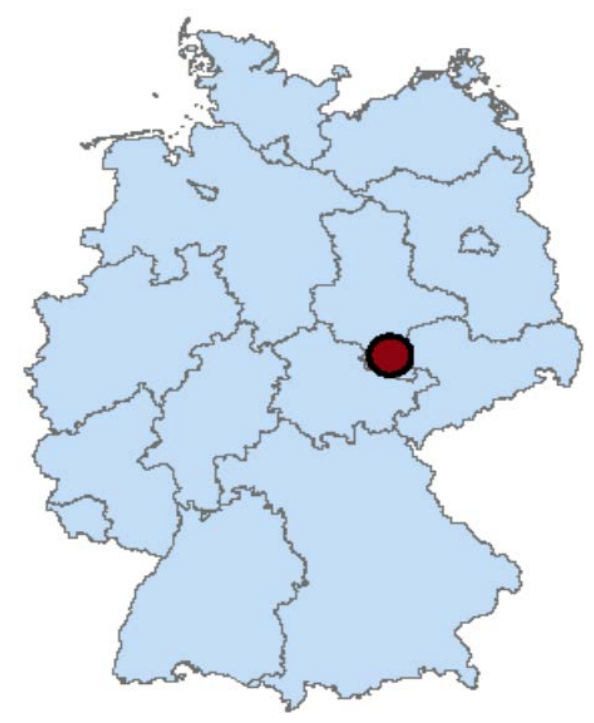

Figure 1: Wind farm location in Germany

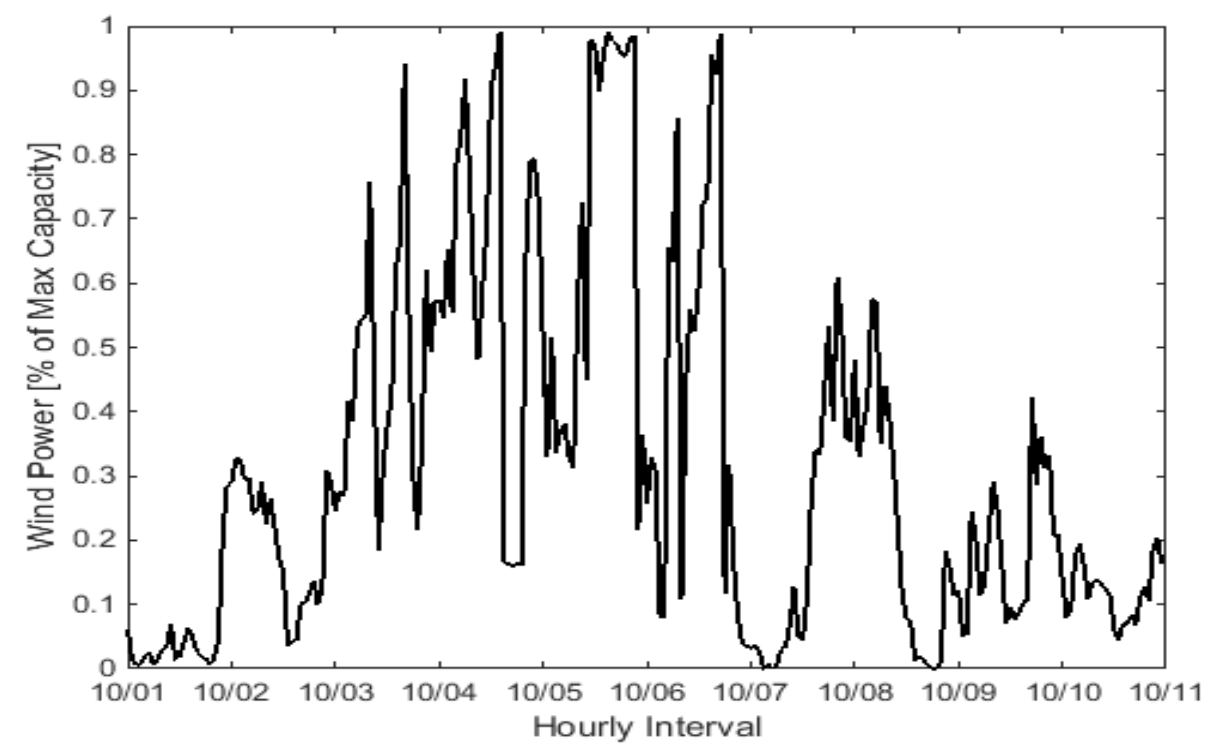

Figure 2: Time series of normalized wind power production over a 10-day episode in Oct. 2012

\subsection{Estimation}

In this section, we present the results of estimating all the considered models in the in-sample period. The calibration of the model consists of two steps. The first step is to determine a proper autoregressive (AR) model that captures the time-varying means of wind power data (Equation 
1). The order of AR term is usually chosen by using the autocorrelation function (ACF) and partial autocorrelation function (PACF). Figure 3 shows that the ACF decays very slow while the PACF becomes insignificant at lag 3, suggesting an AR(3) for modelling the mean dynamic of wind power production. The choice of the AR(3) process is also preferred according to Bayesian information criterion (BIC). After fitting an AR(3), the resulting residuals show no evidence of serial correlation (see Figure A1 in the Appendix). To detect the volatility clustering in the wind power production, the standard step is to further look at the autocorrelations of the squared residuals from the estimated model. Figure 4 plots the squared residuals obtained after fitting the $\operatorname{AR}(3)$ model to the wind power production time series. The volatility clustering effect can be observed in the squared residuals, meaning that large errors tend to follow large errors and small errors tend to follow small errors. The ACF and PACF in Figure 5 also illustrate the serial correlation in the squared residuals, supporting the use of GARCH models for the wind power production. In the remaining section, we will present the estimates of traditional GARCH models and MRS-GARCH model.
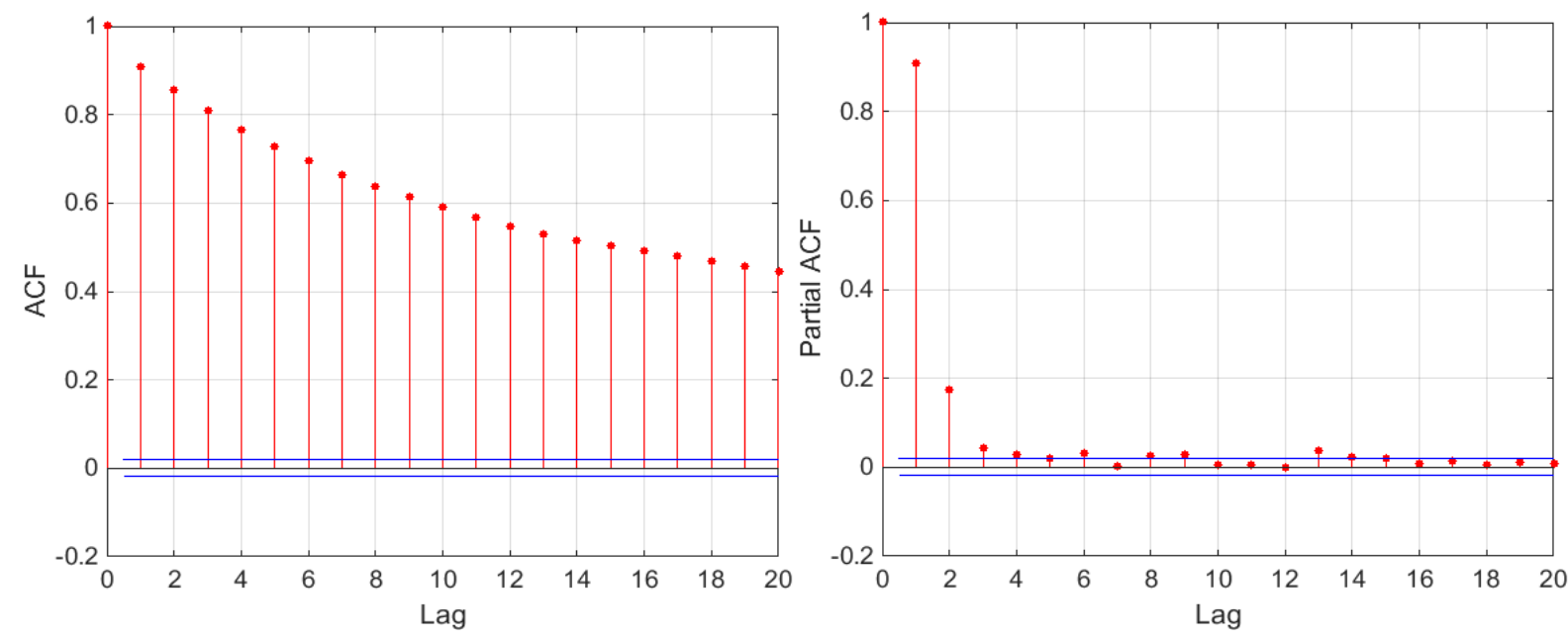

Figure 3: ACF (left) and PACF (right) of wind power production 


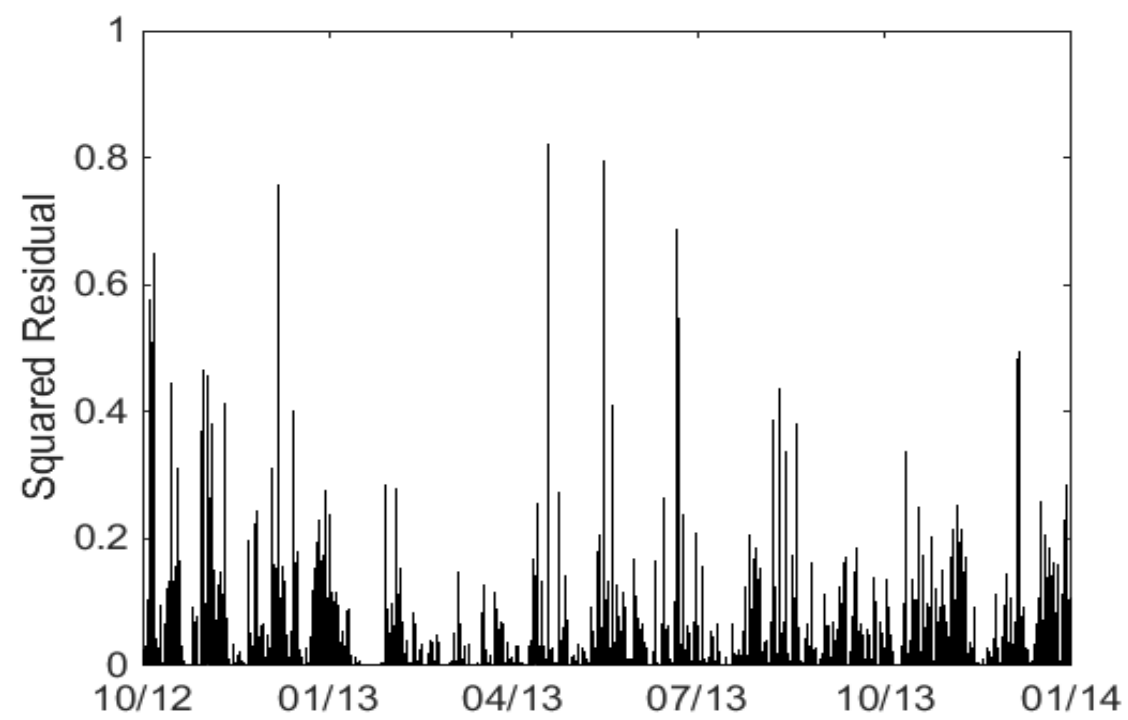

Figure 4: Squared residuals from an AR(3) model
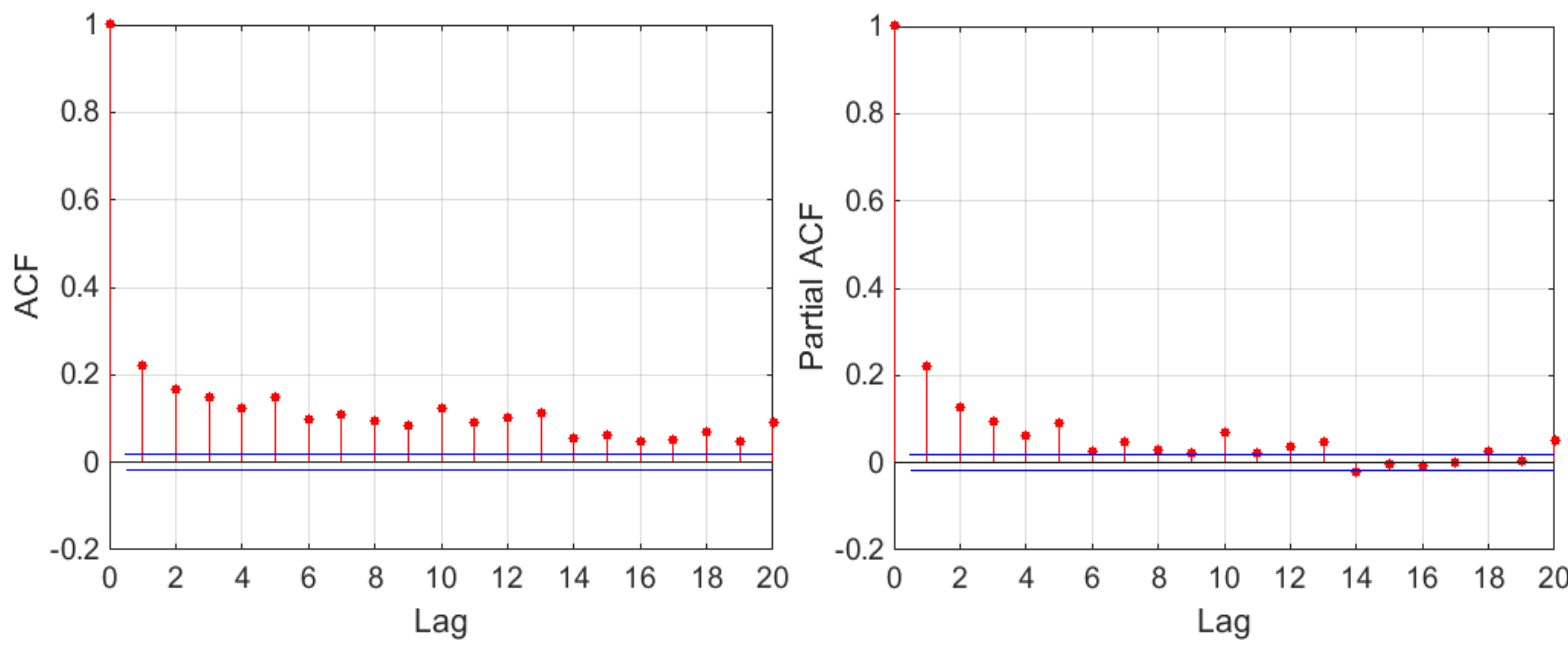

Figure 5: ACF (left) and PACF (right) of the squared residuals of the AR(3)

\section{GARCH models}

We estimate the different GARCH models (such as SGARCH, EGARCH, TGARCH, GJRGARCH and NGARCH) together with AR(3) model of mean process. For the sake of simplicity and to capture the volatility clustering effect sufficiently, we only consider all these GARCH models with $p=q=1$ in our study. Figure A2 in the Appendix shows no correlation in the standardized squared residuals, implying that $\operatorname{GARCH}(1,1)$ well captures the timevarying heteroscedasticity.

The parameter estimates for the traditional GARCH models are presented in Table 1. Almost all parameters for various GARCH models are significant, except for the coefficient of AR(3) 
in the SGARCH and NGARCH. Moreover, the significance of $\gamma$ in these asymmetric GARCH models implies the presence of nonlinear and asymmetric effects in the volatility of wind power production data. Interestingly, the asymmetric effect is opposite to that observed in the volatility of finance data: In financial markets, a negative value of $\gamma$ is often expected for the EGARCH model, suggesting that the negative value of $\varepsilon_{t-i}$ in Equation (5) results in a higher volatility than the positive value. In contrast, we observe a positive $\gamma$ of the EGARCH model from modelling the volatility of wind power production, which means that positive changes lead to a higher volatility than negative ones. In the TGARCH, GJR GARCH, and NGARCH, $\gamma<0$, implying that the impact of a positive change on volatility is amplified compared to negative ones, hence the results are consistent with that from the EGARCH model. This implies that increasing wind power production leads to a higher conditional volatility for the next periods than decreasing ones.

We also present the estimates of the parameters for MRS-GARCH in the last two columns of Table 1. Due to the two-regime structure, 16 parameters need to be estimated in total. The estimates for the conditional mean in both regimes are significant while the estimates of $\omega$ and $\alpha_{1}$ for the conditional variance in regime 1 is close to 0 and thus cannot reject the null of a zero value from $\mathrm{t}$ test. The estimates highlight the existence of two regimes: regime 1 is characterised by a low mean and low volatility (denoted as 'low regime'), the impact of previous shocks on the conditional volatility is nil in this state; regime 2 is characterised by a high mean, high volatility and high persistence in the conditional volatility (denoted as 'high regime'). Table 1 shows that the transition probabilities of both regimes are significant and above 0.83 , indicating that both regimes are persistent and for only less than $20 \%$ chances, the regimes will switch from one to the other. The unconditional probability of wind power production being in the low regime is 0.42 , lower than that of being in the high regime, 0.58 .

Figure 6 illustrate the wind power production and estimated sequence of regimes probability for the MRS-GARCH model. The plotted estimated sequence is the probability of being in regime 1 for wind power production. At most periods, these two regimes do not appear to be clearly distinguished for wind power production except the periods when the wind power production is close to 0 or maximal capacity, with the probability almost 1 or 0 . Normally, we can compare the sequence probabilities with 0.5 to define the regimes for each observation more clearly. Moreover, it is not manifest to differ the volatility of each observation according to the sequence of regimes. The estimated sequence of regimes probability seems to be mainly 
driven by the mean value of wind power production rather than the volatility in our case, i.e., high wind power production in high regime.
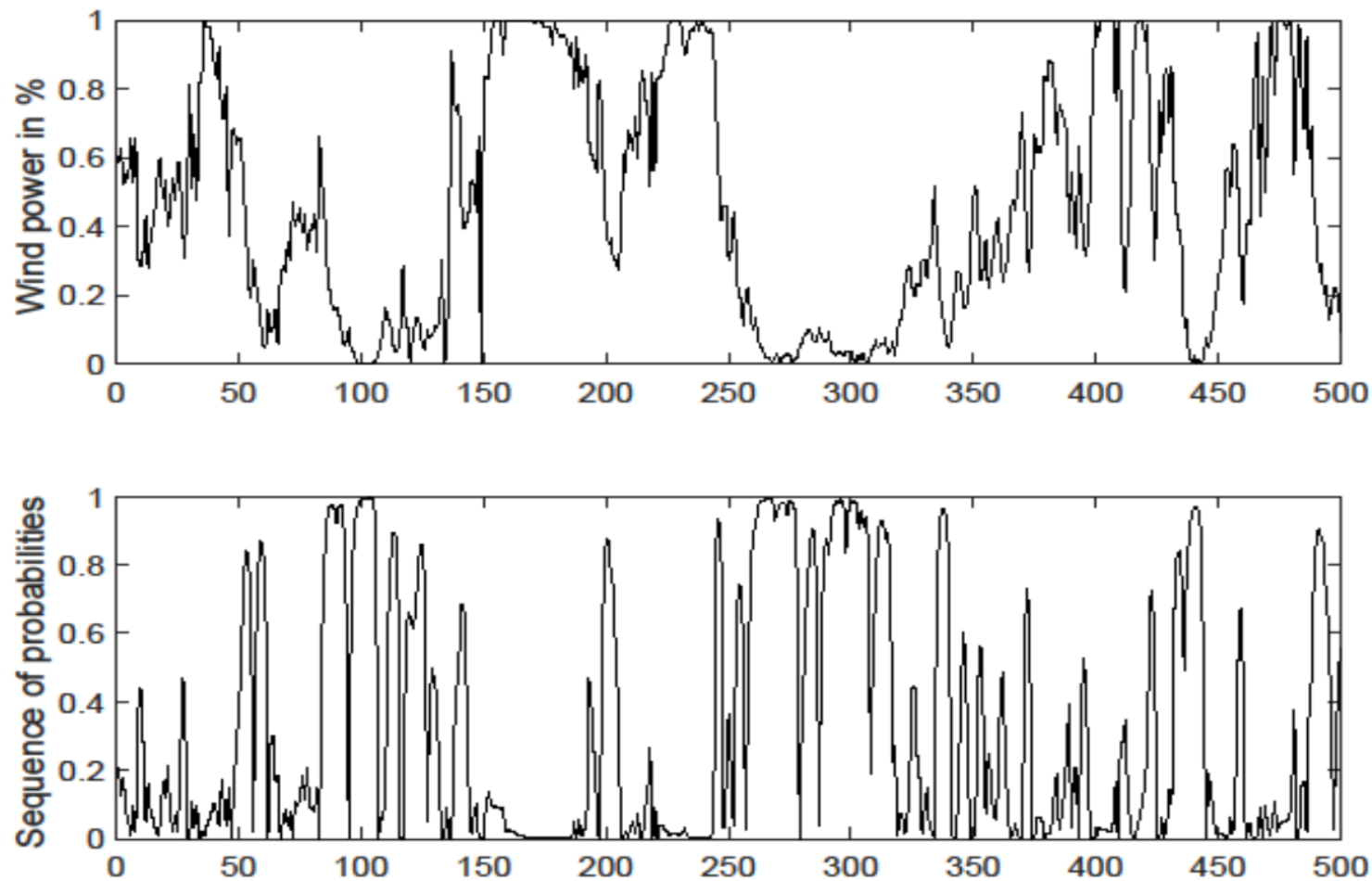

Figure 6: Wind power production and estimated sequence of probabilities of being in regime 1 (i.e., low regime) 
Table 1: Estimation results of traditional GARCH models and MRS-GARCH

\begin{tabular}{|c|c|c|c|c|c|c|c|}
\hline \multirow[t]{2}{*}{ Parameter } & \multirow[t]{2}{*}{ GARCH } & \multirow[t]{2}{*}{ EGARCH } & \multirow[t]{2}{*}{ TGARCH } & \multirow[t]{2}{*}{ GJR-GARCH } & \multirow[t]{2}{*}{ NGARCH } & \multicolumn{2}{|c|}{ MRS-GARCH } \\
\hline & & & & & & Regime 1 & Regime 2 \\
\hline \multicolumn{8}{|c|}{ Mean equation } \\
\hline$c$ & $0.0578^{* * *}$ & $0.0854^{* * *}$ & $0.1102^{* * *}$ & $0.0580^{* * *}$ & $0.0740^{* * *}$ & $0.0005^{* * *}$ & $0.0500^{* * *}$ \\
\hline $\operatorname{AR}(1)$ & $0.8130^{* * *}$ & $0.7893^{* * *}$ & $0.8172^{* * *}$ & $0.7949^{* * *}$ & $0.7977^{* * *}$ & $0.6825^{* * *}$ & $0.6916^{* * *}$ \\
\hline $\operatorname{AR}(2)$ & $0.1149^{* * *}$ & $0.1122^{* * *}$ & $0.1153^{* * *}$ & $0.1186^{* * *}$ & $0.1327^{* * *}$ & $0.0410^{* * *}$ & $0.1709^{* * *}$ \\
\hline $\operatorname{AR}(3)$ & 0.0086 & $0.0457^{* * *}$ & $0.0258^{* * *}$ & $0.0220^{* * *}$ & 0.0143 & $0.0451^{* * *}$ & $0.0745^{* * *}$ \\
\hline \multicolumn{8}{|c|}{ Conditional variance equation } \\
\hline$\omega$ & $0.0002^{* * *}$ & $-0.2137^{* * *}$ & $0.0025^{* * *}$ & $0.0002^{* * *}$ & $0.0001^{* * *}$ & 0.0000 & $0.0015^{* * *}$ \\
\hline$\alpha_{1}$ & $0.2403^{* * *}$ & $0.1893^{* * *}$ & $0.1799^{* * *}$ & $0.1677^{* * *}$ & $0.1477^{* * *}$ & 0.0000 & $0.2066^{* * *}$ \\
\hline$\beta_{1}$ & $0.7587^{* * *}$ & $0.9587^{* * *}$ & $0.8491^{* * *}$ & $0.7842^{* * *}$ & $0.6810^{* * *}$ & $0.4401^{* * *}$ & $0.7933^{* * *}$ \\
\hline$\gamma$ & & $0.2993^{* * *}$ & $-1.0000^{* * *}$ & $-0.5299^{* * *}$ & $-1.0737^{* * *}$ & & \\
\hline$p$ & & & & & & \multicolumn{2}{|c|}{$0.8352^{* * *}$} \\
\hline$q$ & & & & & & \multicolumn{2}{|c|}{$0.8357^{* * *}$} \\
\hline $\mathrm{P}\left(s_{t}=i\right)$ & & & & & & 0.4201 & 0.5799 \\
\hline $\log (L)$ & 11690.55 & 12351.78 & 12394.37 & 12043.92 & 12240.36 & \multicolumn{2}{|c|}{15021.21} \\
\hline
\end{tabular}




\subsection{Comparison of Models}

We begin evaluating the performance of different models by comparing some statistics for both in-sample estimation and out-of-sample forecast. The in-sample goodness-of-fit statistics are presented in Table 2. The log-likelihood suggests that the MRS-GARCH model fits best our wind power production data compared to other state-independent GARCH models. The SGARCH turned out to be the least preferable although it captures well the autocorrelation of the volatility according to Figure A2. TGARCH turns out to be the second best model, followed by EGARCH. The result is also confirmed by the Akaike Information Criterion (AIC) and the Bayesian Information Criterion (BIC), which account for the parsimony of the models. Table 2 also shows that the persistence, which indicates the influence of a shock to volatility, is rather high. In the MRS-GARCH model, the persistence difference in the two regimes is considerable for onshore wind power production observations unlike for financial data.

Having a good in-sample fit does not necessary lead to an accurate and reliable forecast from the models. Moreover, the models with good in-sample fits likely suffer over-fitting or overparametrization problems. To determine the best forecasting model, we conduct the out-ofsample evaluation of one- and five-step ahead volatility forecasts against the realized volatility. Figure 7 shows the realized volatility and one-step ahead forecasted volatilities from MRSGARCH and TGARCH. From the figure, it is not able to determine the best one among the considered models. Therefore, we evaluate the forecasts by using different loss function criteria described in Section 2.3. The results are presented in Table 3. For 1-step ahead volatility forecast, the smallest values of all loss functions except QLIKE are observed for MRS-GARCH model $^{3}$, suggesting that MRS-GARCH model generally outperforms the other GARCH models for volatility forecast of wind power production. EGARCH appears to be second best in the out-of-sample evaluation. Surprisingly, TGARCH turns out to be the worst one in the out-ofsample evaluation although it performed very well in the in-sample evaluation. On the other hand, SGARCH takes the third or fourth place for different selection criteria in the out-ofsample evaluation despite the worst performance in the in-sample fitting. However, the differences for all the models in terms of RMSE and MAE are rather moderate. The result is also found for the volatility forecast at 5 -step ahead.

\footnotetext{
${ }^{3}$ The different rank using QLIKE is expected since its loss function depends on the multiplicative forecast error instead of additive forecast error as in RMSE and MAE. Moreover, this is common in the volatility forecast literature, e.g. Marcucci (2005); Patton (2011); Byun and Cho (2013).
} 
Table 2. In-sample goodness-of-fit statistics

\begin{tabular}{lcccccc}
\hline Model & \# Param. & Persistence & AIC & BIC & $\log (\mathrm{L})$ & Rank \\
\hline SGARCH & 7 & 0.999 & -2.167 & -2.163 & 11690.55 & 6 \\
EGARCH & 8 & 0.959 & -2.290 & -2.284 & 12351.78 & 3 \\
TGARCH & 8 & 0.993 & -2.297 & -2.292 & 12394.37 & 2 \\
GJR-GARCH & 8 & 0.999 & -2.233 & -2.227 & 12043.92 & 5 \\
NGARCH & 8 & 0.999 & -2.269 & -2.264 & 12240.36 & 4 \\
MRS-GARCH & 16 & $0.440 / 0.999$ & -2.783 & -2.773 & 15021.21 & 1
\end{tabular}

Note: The persistence of MRS-GARCH is reported for Regimes 1 and 2, respectively. AIC is calculated as $(-2 \log (L)+2 k) / T$, where $k$ is the number of parameters and $T$ is the number of observations. BIC is calculated as $(-2 \log (L)+k \log (T)) / T$.

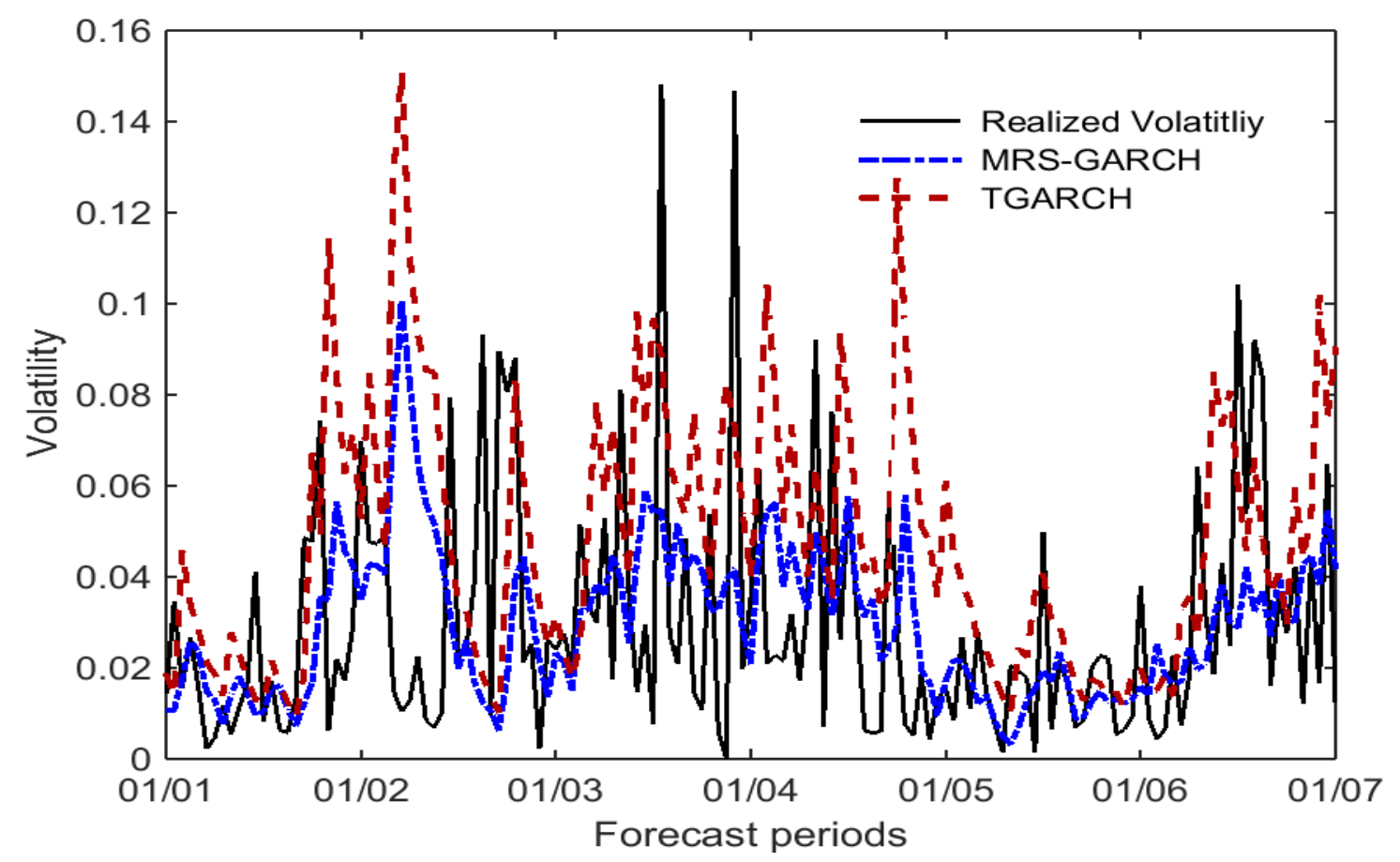

Figure 7: Realized volatility and 1-step forecasted volatility from MRS-GARCH and TGARCH 
Table 3. Out-of-sample evaluation for 1-step ahead volatility forecast

\begin{tabular}{lccccc}
\hline Model & $\begin{array}{c}\text { RMSE } \\
\text { (Rank) }\end{array}$ & $\begin{array}{c}\text { RMSE-LOG } \\
(\text { Rank })\end{array}$ & $\begin{array}{c}\text { MAE } \\
(\text { Rank })\end{array}$ & $\begin{array}{c}\text { MAE-LOG } \\
(\text { Rank })\end{array}$ & $\begin{array}{c}\text { QLIKE } \\
\text { (Rank) }\end{array}$ \\
\hline SGARCH & 0.0335 & 1.9332 & 0.0244 & 0.9195 & -2.4430 \\
& $(3)$ & $(2)$ & $(3)$ & $(4)$ & $(3)$ \\
EGARCH & 0.0328 & 1.9845 & 0.0243 & 0.9117 & -2.4592 \\
& $(2)$ & $(3)$ & $(2)$ & $(2)$ & $(2)$ \\
TGARCH & 0.0416 & 2.3421 & 0.0308 & 1.0139 & -2.4227 \\
& $(6)$ & $(6)$ & $(6)$ & $(6)$ & $(6)$ \\
GJR-GARCH & 0.0390 & 2.1738 & 0.0283 & 0.9687 & -2.4321 \\
NGARCH & $(5)$ & $(5)$ & $(5)$ & $(5)$ & $(4)$ \\
& 0.0344 & 2.0626 & 0.0254 & 0.9134 & -2.4813 \\
MRS-GARCH & $(4)$ & $(4)$ & $(4)$ & $(3)$ & $(1)$ \\
& 0.0295 & 1.7597 & 0.0207 & 0.8406 & -2.4244 \\
\hline
\end{tabular}

Table 4. Out-of-sample evaluation for 5-step ahead volatility forecast

\begin{tabular}{lccccc}
\hline Model & $\begin{array}{c}\text { RMSE } \\
(\text { Rank })\end{array}$ & $\begin{array}{c}\text { RMSE-LOG } \\
(\text { Rank })\end{array}$ & $\begin{array}{c}\text { MAE } \\
(\text { Rank })\end{array}$ & $\begin{array}{c}\text { MAE-LOG } \\
\text { (Rank) }\end{array}$ & $\begin{array}{c}\text { QLIKE } \\
\text { (Rank) }\end{array}$ \\
\hline SGARCH & 0.1260 & 0.5487 & 0.0882 & 0.5694 & -2.3679 \\
& $(3)$ & $(4)$ & $(4)$ & $(4)$ & $(4)$ \\
EGARCH & 0.1001 & 0.4279 & 0.0701 & 0.4770 & -2.3737 \\
& $(2)$ & $(2)$ & $(2)$ & $(2)$ & $(3)$ \\
TGARCH & 0.1732 & 0.6709 & 0.1219 & 0.6300 & -2.3677 \\
& $(6)$ & $(6)$ & $(6)$ & $(6)$ & $(5)$ \\
GJR-GARCH & 0.1600 & 0.6468 & 0.1062 & 0.5951 & -2.3507 \\
& $(5)$ & $(5)$ & $(5)$ & $(5)$ & $(6)$ \\
NGARCH & 0.1281 & 0.4805 & 0.0881 & 0.5133 & -2.4104 \\
& $(4)$ & $(3)$ & $(3)$ & $(3)$ & $(2)$ \\
MRS-GARCH & 0.0982 & 0.4066 & 0.0676 & 0.4696 & -2.4287 \\
& $(1)$ & $(1)$ & $(1)$ & $(1)$ & $(1)$ \\
\hline
\end{tabular}

Note: The volatility at 5-step ahead is calculated as $\sigma_{t+5 \mid t}^{2}=\sum_{j=1}^{5} \hat{\sigma}_{t+j \mid t}^{2}$, where $\hat{\sigma}_{t+j \mid t}^{2}$ is the forecast volatility at $t+j$ given information at $t$. 


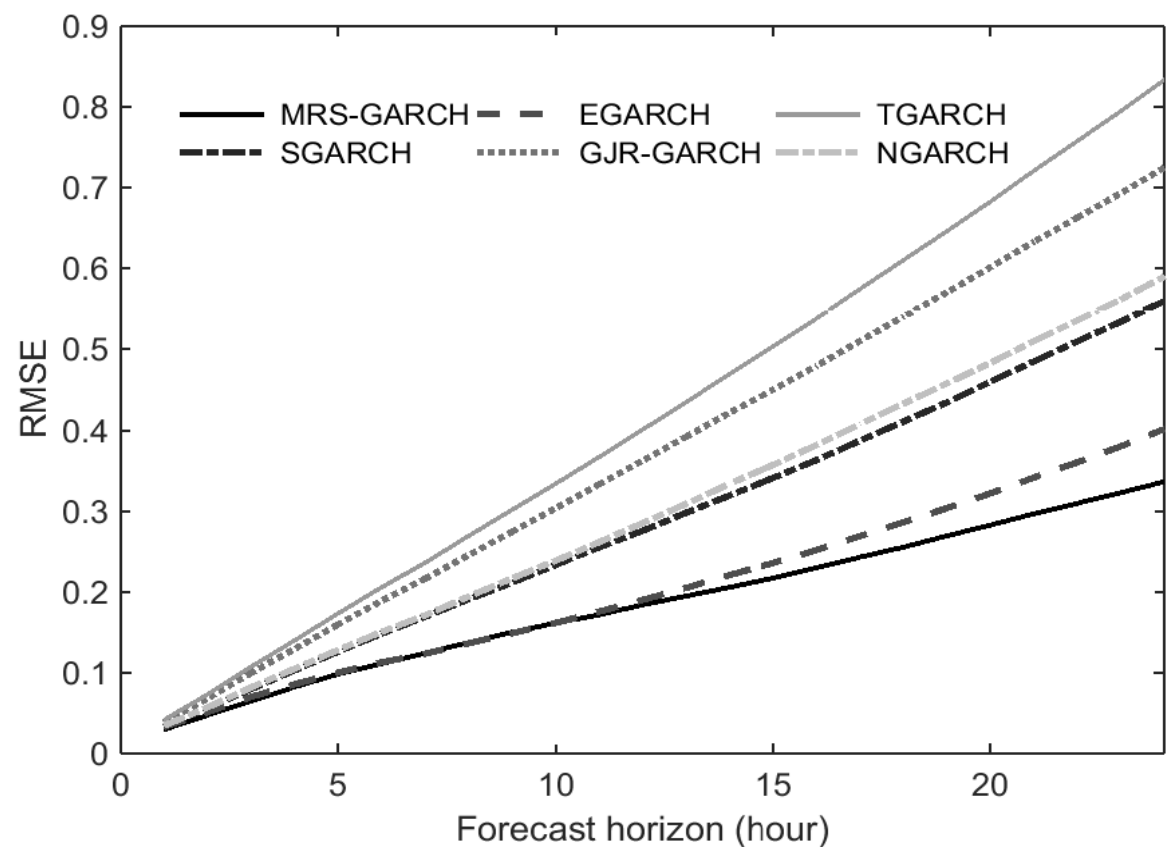

Figure 8: Forecast horizon and root mean square error

Previous literature has shown that the performance of various models might differ with the forecast horizon (Marcucci, 2005). Hence, we plot the RMSE with regard to different forecast horizons (Figure 8). It shows that the RMSE of the MRS-GARCH model is consistently lowest within 24 hours ahead, followed by that of the EGARCH model. This difference from previous literature may be due to the higher frequency of wind power production data. To evaluate the predictive accuracies of the competing models, we use the Diebold-Mariano (DM) test reported in Table 5 where the benchmark is the best model for 1-step ahead horizon (MRS-GARCH). It is observable that the MRS-GARCH model significantly outperforms every other model in terms of square error loss function and absolute error loss function. Moreover, the values of DM test statistics are negative, implying that the MRS-GARCH model has a lower loss than other models. Therefore, the MRS-GARCH model is superior in predicting the volatility of wind power production. Moreover, we are also interested in the predictive accuracy of the EGARCH model, so we also use the EGARCH model as the benchmark in the DM test. The results in Table 6 show the EGARCH model performs significantly better than all other GARCH models except the MRS-GARCH model. The same finding is also observed for 5step ahead volatility forecasts. 
Table 5. Diebold-Mariano Test (1-step ahead)

\begin{tabular}{lcc}
\hline Model & Square error loss & Absolute error loss \\
\hline MRS-GARCH & \multicolumn{2}{c}{ Benchmark } \\
SGARCH & $-2.49^{* * *}$ & $-3.64^{* * *}$ \\
EGARCH & $-2.02^{* * *}$ & $-3.44^{* * *}$ \\
TGARCH & $-4.24^{* * *}$ & $-5.54^{* * *}$ \\
GJR-GARCH & $-3.86^{* * *}$ & $-4.82^{* * *}$ \\
NGARCH & $-2.86^{* * *}$ & $-3.79^{* * *}$ \\
\hline
\end{tabular}

Note: The negative sign implies that the benchmark's loss is lower than that implied by other models. Asterisks $* * *$ denote significance at the 1 per cent level.

Table 6. Diebold-Mariano Test (1-step ahead)

\begin{tabular}{lcc}
\hline Model & Square error loss & Absolute error loss \\
\hline EGARCH & \multicolumn{2}{c}{ Benchmark } \\
MRS-GARCH & $2.01^{* * *}$ & $3.44^{* * *}$ \\
SGARCH & $-0.48^{*}$ & $-0.06^{*}$ \\
TGARCH & $-4.60^{* * *}$ & $-5.81^{* * *}$ \\
GJR-GARCH & $-4.13^{* * *}$ & $-4.67^{* * *}$ \\
NGARCH & $-1.12^{* * *}$ & $-1.58^{* * *}$ \\
\hline
\end{tabular}

Note: The negative sign implies that the benchmark's loss is lower than that implied by other models. Asterisks $* * *$ and $*$ denote significance at the 1 and 10 per cent levels, respectively.

Although the Markov regime switching GARCH model outperforms all the other models, it is observed in Figure 7 that its forecast volatility deviates largely from the realized volatility. It seems that none of the considered models can predict the sudden jumps in hourly volatility of wind power production. This may be due to the fact that wind power production recorded at 10 minutes fluctuates more than the production data at every hour. To understand those two spikes of realized volatility between $3^{\text {rd }}$ and $4^{\text {th }}$ of January, we plot the wind power production recorded at $10 \mathrm{~min}$ (Figure 9). On $3^{\text {rd }}$ of January, wind power production experiences two instantaneous rapid decreases, resulting in the big increases of realized volatility. Thus, jumps at 10 minutes cause a bias in the realized volatility estimator for hourly spot volatility. 


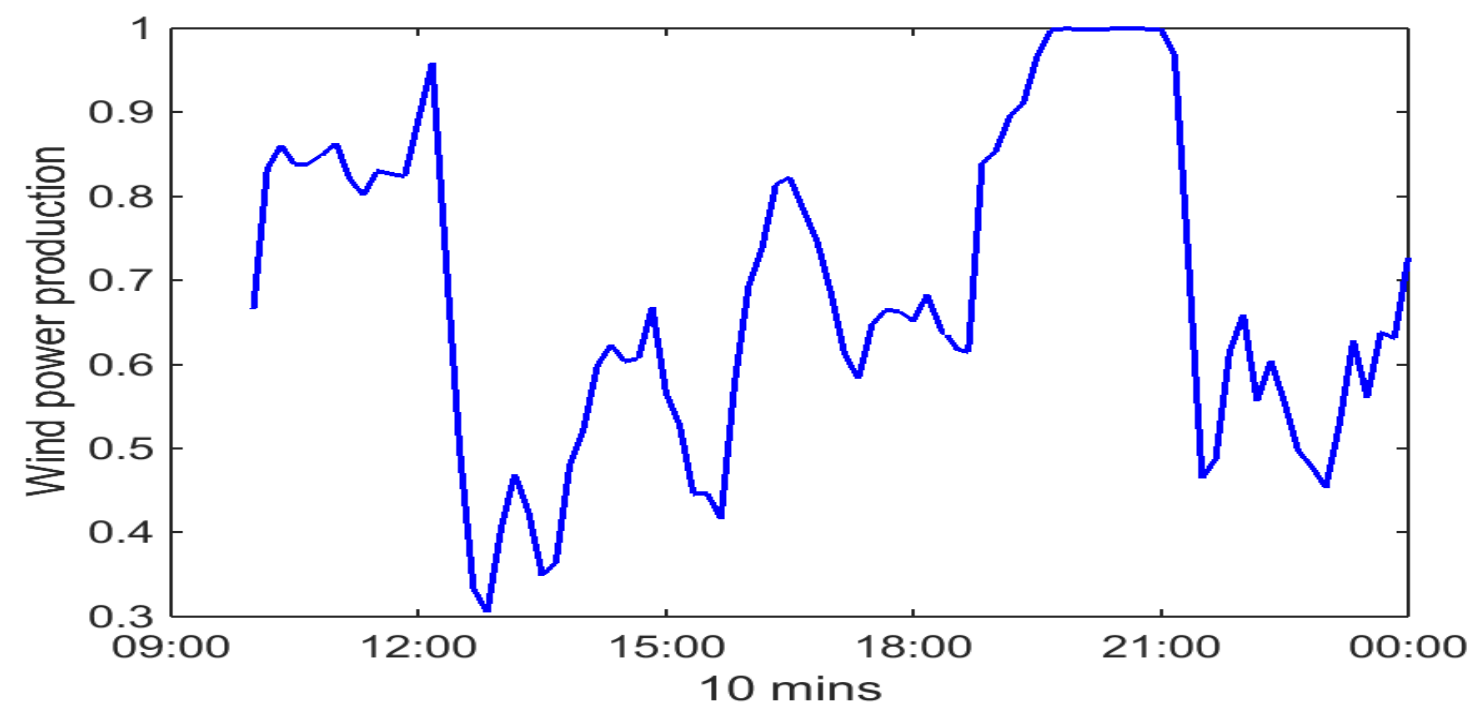

Figure 9: Wind power production on $3^{\text {rd }}$ of January, 2014

\section{Conclusions}

In this article, we have studied the specification of different GARCH models to forecast the volatility of wind power production. Besides the comprehensive comparison of traditional GARCH models in the context of wind power production, an important contribution of this paper is that we propose and examine the use of Markov regime-switching GARCH (MRSGARCH) model to better account for nonlinear and heteroscedastic effects of wind power production. The comparison in the in-sample fitting according to model selection criteria (Loglikelihood, AIC, BIC) suggests that the MRS-GARCH model captures the dynamic process of wind power production better than other models. However, good in-sample fitting does not necessarily imply a good predictive ability in out-of-sample comparison. To evaluate the forecasting performances of different models, the 'true volatility' would be needed. Since the true volatility is latent and unobservable, we resort to the concept of realized volatility introduced in financial market as an ex post proxy of the volatility of wind power production. Empirical results show that the MRS-GARCH model significantly outperforms other GARCH models in forecasting volatility according to a set of statistical loss functions and tests. The difference at 1-step ahead volatility forecast, however, is moderate. Taking into account the computational effort and information gain, the EGARCH model might also be a fair choice to forecast the volatility of wind power production. Moreover, although the MRS-GARCH model has already outperformed other considered models, it cannot predict the abrupt changes in the realized volatility due to the big instantaneous jumps in high frequency wind power production. 
Further research on modelling volatility forecast with jumps to improve the predictive ability may be of considerable interests.

This study is of particular relevance for energy traders to make decision on the balance of supply and demand of wind energy and for investors to develop financial risk management tools against changing weather conditions. Our results support the use of Markov regimeswitching GARCH models for forecasting volatility of wind power production since the model can better capture the dynamic nature of wind power production. The suggested model shows superior performance on the short-term volatility forecast of wind power production and gives more accurate forecast information on the uncertainty about future wind power production. Accordingly, it will be helpful for risk managers and market traders to determine Value-at-Risk of their energy portfolios and to price the related derivatives or insurances on wind power production.

There are several extension of this study that may improve the volatility forecast. First, one may apply the models with heavy-tailed distributions instead of the normal distribution in our case. The assumption of a heavy-tailed distribution might improve the results by considering the fact that the wind power production data are bounded and mass data points are generated around the boundary. Second, the Markov regime-switching model was only incorporated with a standard GARCH model in our case. It would be interesting to consider the combination with other asymmetric GARCH models as well. Last but not least, given substantial geographical difference of wind conditions, the validation of models using wind farm data from different locations is of great importance and relevance to its potential implementation for energy traders and investors.

\section{References}

Alexandridis, A., Zapranis, A. (2013): Wind derivatives: Modelling and pricing. Computational Economics 41: 299-326.

Andersen, T. G., Bollerslev, T., Diebold, F. X., Labys, P. (2003). Modelling and forecasting realized volatility. Econometrica, 71(2): 579-625.

Andersen, T. G., Bollerslev, T., \& Lange, S. (1999). Forecasting financial market volatility: Sample frequency vis-a-vis forecast horizon. Journal of Empirical Finance, 6(5): 457-477.

Anastasiades, G., McSharry, P. (2013): Quantile forecasting of wind power using variability indices. Energies 6: 662-695. 
Balcilar, M., Gupta, R., Miller, S. (2015): Regime switching model of US crude oil and stock market prices: 1859 to 2013. Energy Economics, 49: 317-327.

Bilgili, M., Sahin, B., Yasar, A. (2007): Application of artificial neural networks for the wind speed prediction of target station using reference stations data. Renewable Energy 32 (14): $2350-2360$.

Bollerslev, T. (1986). Generalized autoregressive conditional heteroskedasticity. Journal of Econometrics, 31(3): 307-327.

Bollerslev, T., Ghysels, E. (1996). Periodic autoregressive conditional heteroscedasticity. Journal of Business \& Economic Statistics, 14(2): 139-151.

Bremnes, J. B. (2004). Probabilistic wind power forecasts using local quantile regression. Wind Energy, 7(1): 47-54.

Brownlees, C., Engle, R., Kelly, B. (2011). A Practical Guide to Volatility Forecasting Through Calm and Storm. Journal of Risk, 14(2): 1-20.

Brown, B.G., Katz, R.W., Murphy, A.H. (1984): Time series models to simulate and forecast wind speed and wind power. Journal of Climate and Applied Meteorology, 23(8): 1184-1195.

Byun, S. J., Cho, H. (2013). Forecasting carbon futures volatility using GARCH models with energy volatilities. Energy Economics, 40: 207-221.

Economist Intelligence Unit (2011): Managing the risk in renewable energy. http://www.economistinsights.com/energy/analysis/managing-risk-renewable-energy

Engle, R. F., Ng, V. K. (1993). Measuring and testing the impact of news on volatility. The Journal of Finance, 48(5): 1749-1778.

Diebold, F., Mariano, R. (1995). Comparing Predictive Accuracy. Journal of Business \& Economic Statistics, 13(3): 253-263.

Giebel, G., Brownsword, R., Kariniotakis, G., Denhard, M., Draxl, C. (2011) The state-of-theart in short-term prediction of wind power: A literature overview. Technical Report, ANEMOS.plus.

Glosten, L. R., Jagannathan, R., Runkle, D. E. (1993). On the relation between the expected value and the volatility of the nominal excess return on stocks. The Journal of Finance, 48(5): $1779-1801$. 
GWEC (2014). Global wind report — annual market update 2013. Global Wind Energy Council. http://www.gwec.net/publications/global-wind-report-2/global-wind-report-2013/

GWEC (2015). Global wind statistics. Issued 10.2.2015. Global Wind Energy Council. http://www.gwec.net/global-figures/graphs/

Hamilton, J. D. (1989). A new approach to the economic analysis of nonstationary time series and the business cycle. Econometrica, 57(2): 357-384.

Hentschel, L. (1995). All in the family nesting symmetric and asymmetric GARCH models. Journal of Financial Economics, 39(1), 71-104.

Klaassen, F. (2002). Improving GARCH volatility forecasts with regime-switching GARCH. Empirical Economics, 27(2): 363-394.

Kusiak, A., Zhang, Z., Verma, A. (2013): Prediction, operations and condition monitoring in wind energy. Energy, 60: 1-12.

Lammerding, M., Stephan, P., Trede, M., Wilfling, B. (2013). Speculative bubbles in recent oil price dynamics: Evidence from a Bayesian Markov-switching state-space approach. Energy Economics, 36: 491-502.

Lau, A., McSharry, P. (2010): Approaches for multi-step density forecasts with application to aggregated wind power. The Annals of Applied Statistics, 4(3): 1311-1341.

Liu, H., Erdem, E., \& Shi, J. (2011). Comprehensive evaluation of ARMA-GARCH (-M) approaches for modelling the mean and volatility of wind speed. Applied Energy, 88(3): 724732.

Marcucci, J. (2005). Forecasting stock market volatility with regime-switching GARCH models. Studies in Nonlinear Dynamics \& Econometrics, 9(4): 1558-3708.

Monteiro, C., Bessa, R., Miranda, V., Botterud, A., Wang, J., Conzelmann, G. (2009). Wind power forecasting: State-of-the-art 2009. Technical Report, Argonne National Laboratory (ANL).

Nelson, D. B. (1991). Conditional heteroskedasticity in asset returns: A new approach. Econometrica, 59: 347-370.

Patton, A. J. (2011). Volatility forecast comparison using imperfect volatility proxies. Journal of Econometrics, 160(1): 246-256. 
Pinson, P. (2012). Very-short-term probabilistic forecasting of wind power with generalized logit-normal distributions. Journal of the Royal Statistical Society: Series C (Applied Statistics), 61(4), 555-576.

Pinson P, Chevallier C, Kariniotakis G. (2007) Trading wind generation with short-term probabilistic forecasts of wind power. IEEE Transactions on Power Systems, 22:1148-1156.

Pinson, P., Christensen, L. E. A., Madsen, H., Sørensen, P. E., Donovan, M. H., Jensen, L. E. (2008). Regime-switching modelling of the fluctuations of offshore wind generation. Journal of Wind Engineering and Industrial Aerodynamics, 96(12): 2327-2347.

Poon, S. H., Granger, C. W. (2003). Forecasting volatility in financial markets: A review. Journal of Economic Literature, 41(2), 478-539.

Ritter, M., Shen, Z., López Cabrera, B., Odening, M., Deckert, L. (2015): Designing an index for assessing wind energy potential. Renewable Energy.

Šaltytė-Benth, J., Benth, F.E. (2010): Analysis and modelling of wind speed in New York. Journal of Applied Statistics, 37(6): 893-909.

Song, Z., Jiang, Y., Zhang, Z. (2014). Short-term wind speed forecasting with Markovswitching model. Applied Energy, 130: 103-112.

Tastu, J., Pinson, P., Trombe, P. J., Madsen, H. (2014). Probabilistic forecasts of wind power generation accounting for geographically dispersed information. IEEE Transactions on Smart Grid, 5(1): 480-489.

Trombe, P. J., Pinson, P. (2012). High-resolution forecasting of wind power generation with regime switching models and off-site observations. Technical University of Denmark.

Trombe, P. J., Pinson, P., Madsen, H. (2012). A general probabilistic forecasting framework for offshore wind power fluctuations. Energies, 5(3): 621-657.

Tsay, R. S. (2010). Analysis of financial time series. Wiley series in probability and statistics. Wiley.

Zakoian, J. M. (1994). Threshold heteroskedastic models. Journal of Economic Dynamics and Control, 18(5): 931-955. 


\section{Appendix}
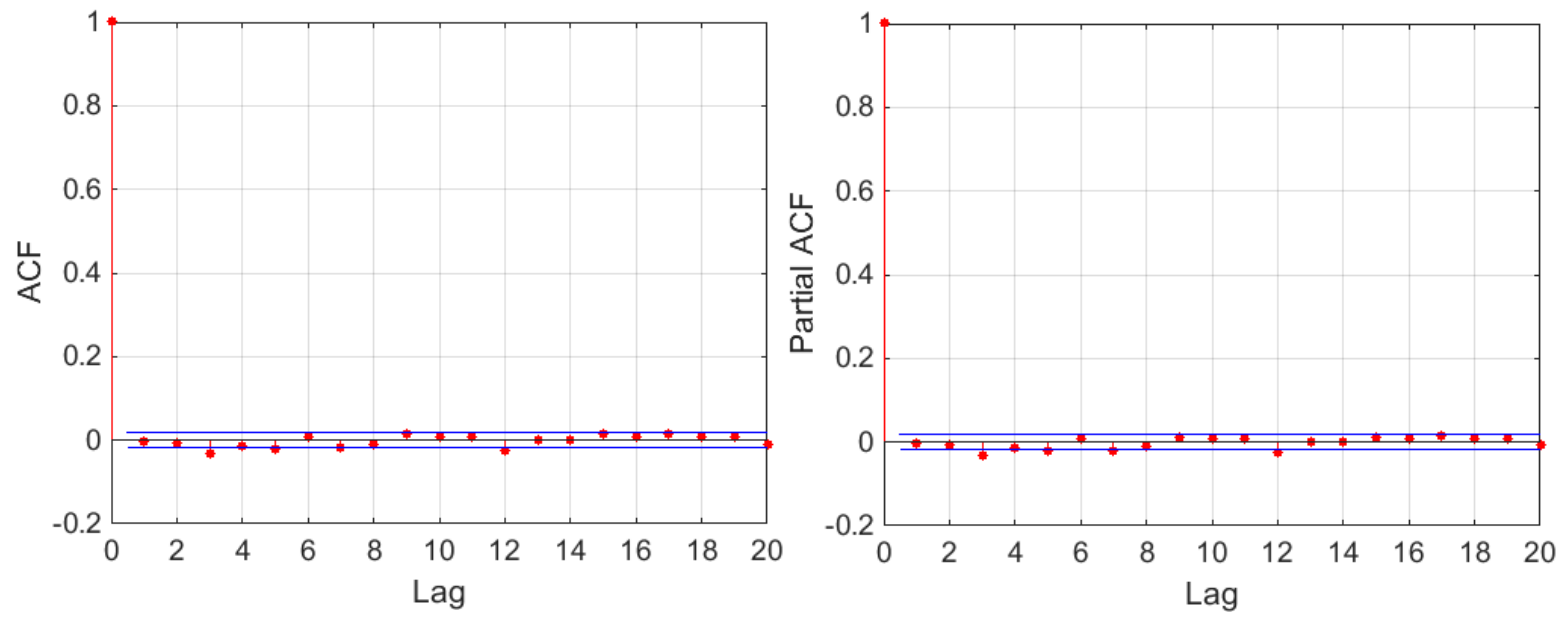

Figure A1: ACF (left) and PACF (right) of residuals from a AR(3) model for wind power production
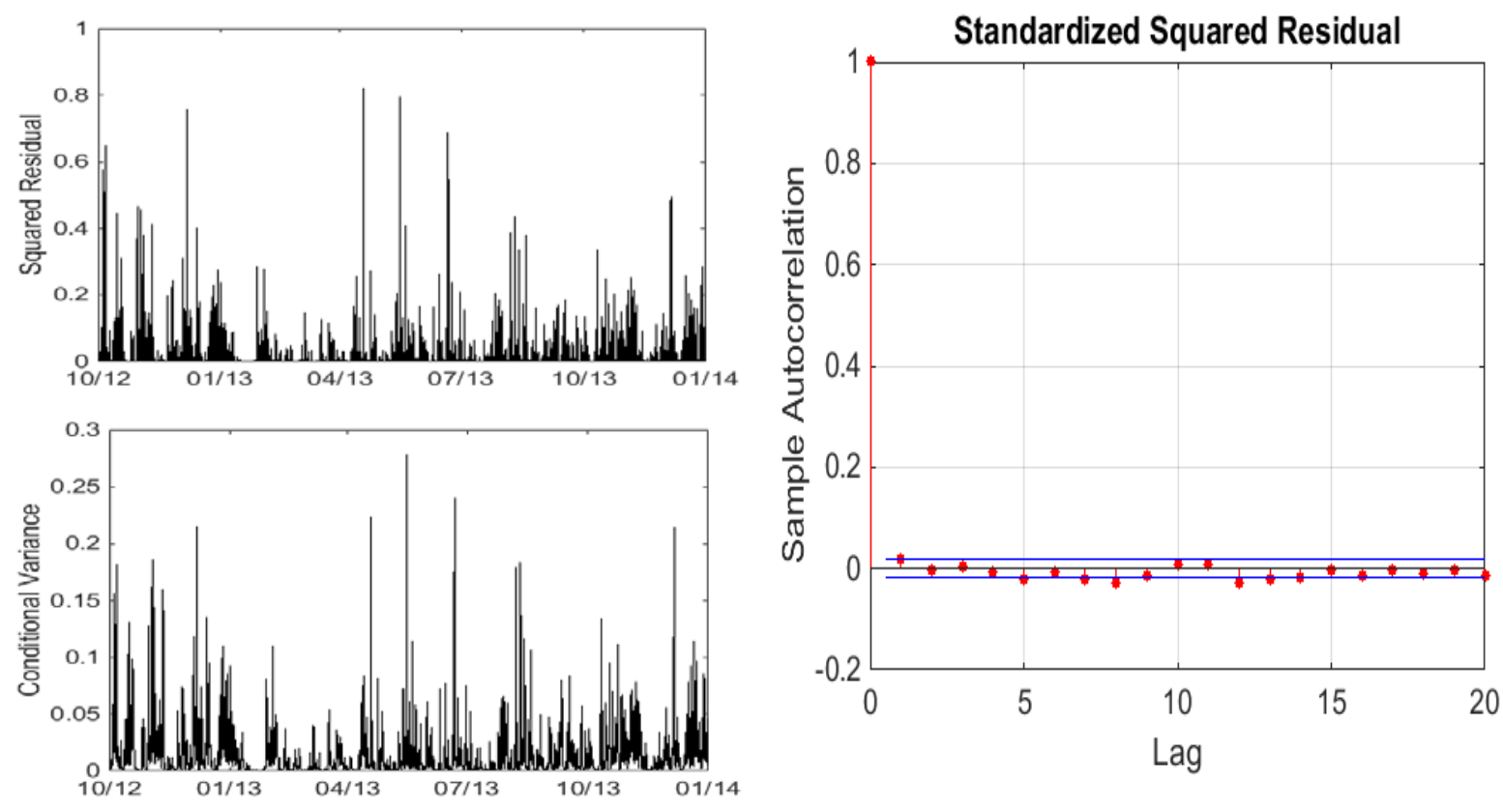

Figure A2: Square residuals (left, top), conditional variance estimated from $\operatorname{SGARCH}(1,1)$ (left, bottom), and the ACF of standardized squared residual (right) 


\section{SFB 649 Discussion Paper Series 2015}

For a complete list of Discussion Papers published by the SFB 649, please visit http://sfb649.wiwi.hu-berlin.de.

001 "Pricing Kernel Modeling" by Denis Belomestny, Shujie Ma and Wolfgang Karl Härdle, January 2015.

002 "Estimating the Value of Urban Green Space: A hedonic Pricing Analysis of the Housing Market in Cologne, Germany" by Jens Kolbe and Henry Wüstemann, January 2015.

003 "Identifying Berlin's land value map using Adaptive Weights Smoothing" by Jens Kolbe, Rainer Schulz, Martin Wersing and Axel Werwatz, January 2015.

004 "Efficiency of Wind Power Production and its Determinants" by Simone Pieralli, Matthias Ritter and Martin Odening, January 2015.

005 "Distillation of News Flow into Analysis of Stock Reactions" by Junni L. Zhang, Wolfgang K. Härdle, Cathy Y. Chen and Elisabeth Bommes, January 2015.

006 "Cognitive Bubbles" by Ciril Bosch-Rosay, Thomas Meissnerz and Antoni Bosch-Domènech, February 2015.

007 "Stochastic Population Analysis: A Functional Data Approach" by Lei Fang and Wolfgang K. Härdle, February 2015.

008 "Nonparametric change-point analysis of volatility" by Markus Bibinger, Moritz Jirak and Mathias Vetter, February 2015.

009 "From Galloping Inflation to Price Stability in Steps: Israel 1985-2013" by Rafi Melnick and till Strohsal, February 2015.

010 "Estimation of NAIRU with Inflation Expectation Data" by Wei Cui, Wolfgang K. Härdle and Weining Wang, February 2015.

011 "Competitors In Merger Control: Shall They Be Merely Heard Or Also Listened To?" by Thomas Giebe and Miyu Lee, February 2015.

012 "The Impact of Credit Default Swap Trading on Loan Syndication" by Daniel Streitz, March 2015.

013 "Pitfalls and Perils of Financial Innovation: The Use of CDS by Corporate Bond Funds" by Tim Adam and Andre Guettler, March 2015.

014 "Generalized Exogenous Processes in DSGE: A Bayesian Approach" by Alexander Meyer-Gohde and Daniel Neuhoff, March 2015.

015 "Structural Vector Autoregressions with Heteroskedasticy" by Helmut Lütkepohl and Aleksei Netšunajev, March 2015.

016 "Testing Missing at Random using Instrumental Variables" by Christoph Breunig, March 2015.

017 "Loss Potential and Disclosures Related to Credit Derivatives - A CrossCountry Comparison of Corporate Bond Funds under U.S. and German Regulation" by Dominika Paula Gałkiewicz, March 2015.

018 "Manager Characteristics and Credit Derivative Use by U.S. Corporate Bond Funds" by Dominika Paula Gałkiewicz, March 2015.

019 "Measuring Connectedness of Euro Area Sovereign Risk" by Rebekka Gätjen Melanie Schienle, April 2015.

020 "Is There an Asymmetric Impact of Housing on Output?" by Tsung-Hsien Michael Lee and Wenjuan Chen, April 2015.

021 "Characterizing the Financial Cycle: Evidence from a Frequency Domain Analysis" by Till Strohsal, Christian R. Proaño and Jürgen Wolters, April 2015.

\section{SFB 649, Spandauer Straße 1, D-10178 Berlin http://sfb649.wiwi.hu-berlin.de}




\section{SFB 649 Discussion Paper Series 2015}

For a complete list of Discussion Papers published by the SFB 649, please visit http://sfb649.wiwi.hu-berlin.de.

022 "Risk Related Brain Regions Detected with 3D Image FPCA" by Ying Chen, Wolfgang K. Härdle, He Qiang and Piotr Majer, April 2015.

023 "An Adaptive Approach to Forecasting Three Key Macroeconomic Variables for Transitional China" by Linlin Niu, Xiu Xu and Ying Chen, April 2015.

024 "How Do Financial Cycles Interact? Evidence from the US and the UK" by Till Strohsal, Christian R. Proaño, Jürgen Wolters, April 2015.

025 "Employment Polarization and Immigrant Employment Opportunities" by Hanna Wielandt, April 2015.

026 "Forecasting volatility of wind power production" by Zhiwei Shen and Matthias Ritter, May 2015. 